\title{
Experimental study of the Effect of Fuel Injector nozzle holes on Direct Injection Diesel Engine
}

\author{
Rohit Sharma $^{1}$, Rana Ranjit Singh ${ }^{1}$ and Shailendra Kumar Vishwakarma ${ }^{1}$ \\ ${ }^{I}$ M.Tech Students, Department of Mechanical Engineering, National Institute of Technology, Warangal-506004
}

\begin{abstract}
Fuel injection parameters play an important role in diesel engine performance for obtaining proper combustion. The performance and emission characteristics of diesel engine depend on many parameters. The important parameters which influence the performance and emission of diesel engine are fuel injection pressure, fuel nozzle holes and its size. An experimental study was performed on a light duty direct injection diesel engine at 200 bar, 220 bar and 240 bar injection pressure to study its effect on performance and emission. The injection pressure was changed by adjusting the fuel injector spring tension. Future emission legislation will require substantial reductions of $N O x$ and Smoke emissions from diesel engines. The combustion and formation in a diesel engine is governed mainly by spray formation and mixing. Important parameters governing these are droplet size, distribution concentration and injection velocity. Smaller orifices are believed to give smaller droplet size, even with reduce injection pressure, which leads to better fuel atomization, faster evaporation and better mixing. The performance and emission characteristics were presented graphically to conclude that they were found better with 5 hole nozzle of $\varnothing=0.2 \mathrm{~mm}$ at the fuel injection pressure 220 bar for the light duty engine.
\end{abstract}

Keywords: Diesel engines, performance, fuel injection parameters, $B S F C, N O_{x}$ emission.

\section{Introduction}

Diesel engines are the primary source of power for the light, medium and heavy duty applications and as such there can be no replacement for it in agriculture and transportation sectors. The advantages of diesel engines are high fuel efficiency, reliability and durability. In present diesel engines, fuel injection systems have designed to obtain higher injection pressure. So, it is aimed to decrease the exhaust emissions by increasing efficiency of diesel engines. When fuel injection pressure is low, fuel particle diameters will enlarge and ignition delay period during the combustion will increase $[2,3]$.This situation leads to inefficient combustion in the engine and causes the increase in $\mathrm{NO}_{\mathrm{x}}, \mathrm{CO}$ emissions. Engine performance will be decrease since combustion process goes to a bad condition. When injection pressure increased of fuel particle diameters will become small. Since formation of mixing of fuel to air becomes better during ignition period, engine performance will be increase. If injection pressure is too higher, ignition delay period becomes shorter. Possibilities of homogeneous mixing decrease and combustion efficiency falls down [4]. Therefore, smoke is formed at exhaust of engine.

The geometry of the nozzle in an injector plays a vital role in controlling diesel spray atomization and combustion. In order to bring fuel droplet size small, the nozzle-hole size is required to be reduced to produce smaller droplets [1]. By decreasing the nozzle hole size, the spray tip penetration is reduced due to the low spray momentum. High injection pressures with small nozzles are common in the modern diesel engine as they reduce injection duration and improve combustion efficiency[5].Computational simulations were performed to study the effect of reduced nozzle-hole size and nozzle tip hole configuration on the combustion characteristics of a high speed direct injection diesel engine [7].

In this work the effects of fuel injection pressure and fuel nozzle holes are experimentally studied on performance and emission characteristics of single cylinder light duty direct injection diesel engine.

\section{Experimental Setup And Procedure}

The experiments were conducted on a single cylinder, 4 stroke, constant speed, water cooled diesel engine was coupled to Hydraulic dynamometer, variable compression ratio, direct injection compression ignition engine with hemispherical open combustion chamber. The general specifications of the engine are given in Table-I. The engine is equipped with thermocouples to measure the temperature of water, air and gas, Rotameter to measure the water flow rate and manometer to measure air flow and fuel flow. Exhaust gas analysis was performed using Netel make five gas exhaust analyzer. An exhaust analyzer is used to measure $\mathrm{CO}, \mathrm{HC}, \mathrm{NO}_{\mathrm{x}}$ and $\mathrm{O}_{2}$. The measuring range and resolution are given in the Table. III. A Hartridge smoke meter was attached to exhaust pipe to measure smoke levels. The experimental set up as shown in Fig.1. 
Table I. Engine Specification

\begin{tabular}{|c|c|}
\hline Manufacturer & Kirloskar engines Ltd., Pune, India \\
\hline Engine Type & $\begin{array}{c}\text { Four stroke, single cylinder, } \\
\text { constant } \\
\text { speed, compression ignition engine }\end{array}$ \\
\hline Rated power & $3.7 \mathrm{~kW}$ at $1500 \mathrm{rpm}$ \\
\hline Bore & $80 \mathrm{~mm}$ \\
\hline Stroke & $110 \mathrm{~mm}$ \\
\hline Swept volume & $553 \mathrm{cc}$ \\
\hline $\begin{array}{c}\text { Compression } \\
\text { Ratio }\end{array}$ & 16.5 \\
\hline $\begin{array}{c}\text { Mode of } \\
\text { injection }\end{array}$ & Direct injection \\
\hline Cooling system & Water \\
\hline Dynamometer & Hydraulic dynamometer \\
\hline
\end{tabular}

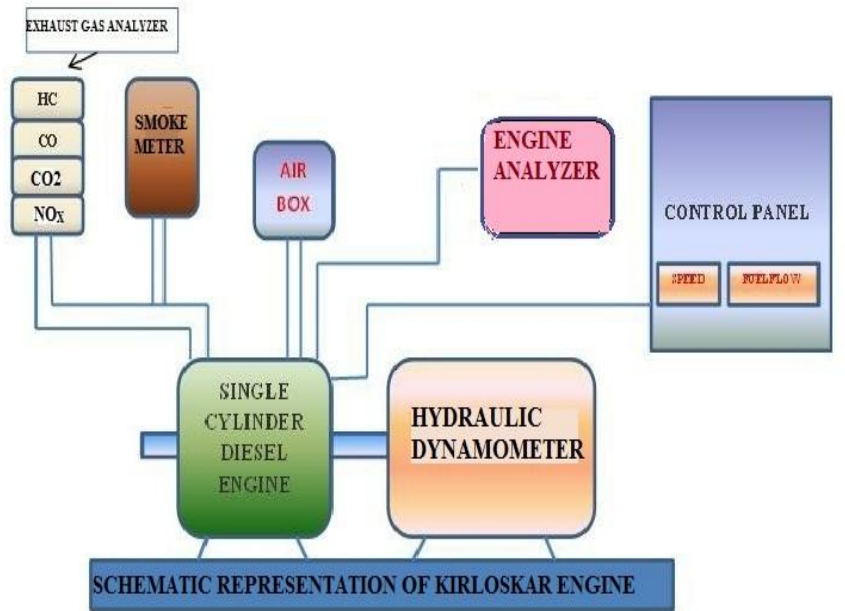

Fig-1.Schematic representation of experimental set up.

Table Ii: Properties Of Diesel Fuel

\begin{tabular}{|c|c|c|c|}
\hline $\begin{array}{c}\text { Cetane } \\
\text { number }\end{array}$ & Density at $30^{\circ} \mathrm{C}$ & $\begin{array}{c}\text { Viscosity at } \\
40^{\circ} \mathrm{C}\end{array}$ & Calorific Value \\
\hline 53 & $836 \mathrm{~kg} / \mathrm{m}^{3}$ & $2.68 \mathrm{~mm}^{2} / \mathrm{s}$ & $43626 \mathrm{KJ} / \mathrm{kg}$ \\
\hline
\end{tabular}

The details of the nozzles and fuel injection pressures employed are given in Table-IV. Constant speed performance tests were conducted maintaining jacket water temperature at $45^{\circ} \mathrm{C}$ in order to maintain steady state conditions. The fuel injection pressure was set to $200 \mathrm{bar}, 220 \mathrm{bar}$ and $240 \mathrm{bar}$. Injection pressure was changed by means of adjusting the injector spring tension as shown in Fig.2. Each trial was repeated three times and on different days, enough care was taken to load the engine accurately at each step of load and also to maintain ambient conditions constant. The results of the three repetitions were averaged to decrease the error/uncertainty.

Table Iv: Details Of Fuel Injection Parameters

\begin{tabular}{|c|c|c|c|}
\hline $\begin{array}{c}\text { Nozzle } \\
\text { type }\end{array}$ & $\begin{array}{c}\text { Fuel Injection } \\
\text { Pressure, bar }\end{array}$ & No. of holes & $\begin{array}{c}\text { Diameter of } \\
\text { each hole }\end{array}$ \\
\hline NH1 & 200,220 and 240 & 3 & $0.28 \mathrm{~mm}$ \\
\hline NH2 & 200,220 and 240 & 5 & $0.20 \mathrm{~mm}$ \\
\hline
\end{tabular}


TABLE-III. EXHAUST GAS ANALYZER SPECIFICATION

\begin{tabular}{|c|c|c|c|}
\hline $\begin{array}{c}\text { Measuring } \\
\text { item }\end{array}$ & $\begin{array}{c}\text { Measuring } \\
\text { method }\end{array}$ & $\begin{array}{c}\text { Measuring } \\
\text { range }\end{array}$ & Resolution \\
\hline $\mathrm{CO}$ & NDIR & $0-9.99 \%$ & $0.01 \%$ \\
\hline $\mathrm{HC}$ & NDIR & $0-5000 \mathrm{ppm}$ & $1 \mathrm{ppm}$ \\
\hline $\mathrm{CO}_{2}$ & NDIR & $0-20 \%$ & $0.10 \%$ \\
\hline $\mathrm{O}_{2}$ & Electro chemical & $0-25 \%$ & $0.01 \%$ \\
\hline $\mathrm{NOx}$ & Electro chemical & $0-5000 \mathrm{ppm}$ & $1 \mathrm{ppm}$ \\
\hline
\end{tabular}

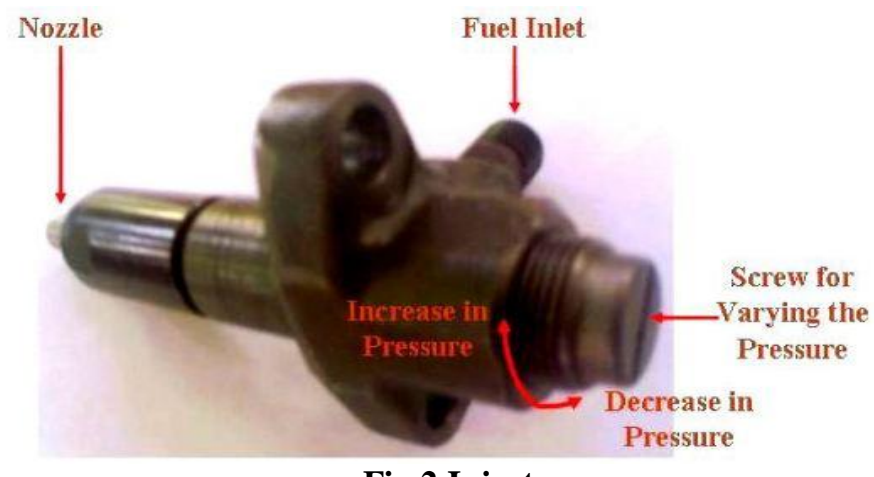

Fig.2 Injector

\section{RESULT AND DISCUSSION}

Experiments are performed on the diesel engine by varying fuel injection pressures (IP) and nozzle hole geometry to arrive at optimum configuration. The results are discussed below

\section{A. Effect on Brake Thermal Efficiency (BTE)}

Effect of nozzle hole geometry for NH1(3 hole nozzle) and $\mathrm{NH} 2(5$ hole nozzle) on brake thermal efficiency is as shown in Figs.3-4 respectively. It was found that, nozzle hole geometry has significant influences on droplet size (spray) penetration. From Figs.3-4 at corresponding IP say 220 bar, it was noticed that, rise in thermal efficiency with increase in nozzle hole. This was due to increase in nozzle hole was responsible to rise in air fuel mixing, fuel vaporization and improved combustion and heat release rate. Thus, in view of this BTE rises with number of hole. From the Fig.4 below, it was observed that BTE $26.65 \%$ and $26.18 \%$ was higher at $\mathrm{NH} 2,220$ bar injection pressure, and full load and $80 \%$ load respectively. The possible reason may be stated as, increase in IP leads to better atomization of fuel, improved spray characteristics and reduced physical delay period; which improved premixed combustion and rapid combustion rate. Owing to this, increase in brake thermal efficiency was observed. However too high IP will lead to delayed injection, negating gain due too high IP. Also, too high IP may responsible to higher velocity of droplet which will pass away without mixing air properly and lower brake thermal efficiency due to improper combustion. It has also been observed that the smaller the orifice, the shorter the ignition delay. The smaller orifices also improve the mixing, which is shown by shorter combustion duration. This results in reduction of the heat and time losses, resulting in a higher brake thermal efficiency, i.e. lower brake specific fuel consumption. One of the nozzles with smaller orifices $(\varnothing 0.20 \mathrm{~mm})$ has improved combustion for all of the test cases, resulting in an increase in fuel conversion efficiency compared to the reference nozzle (Ø0.28 mm). 


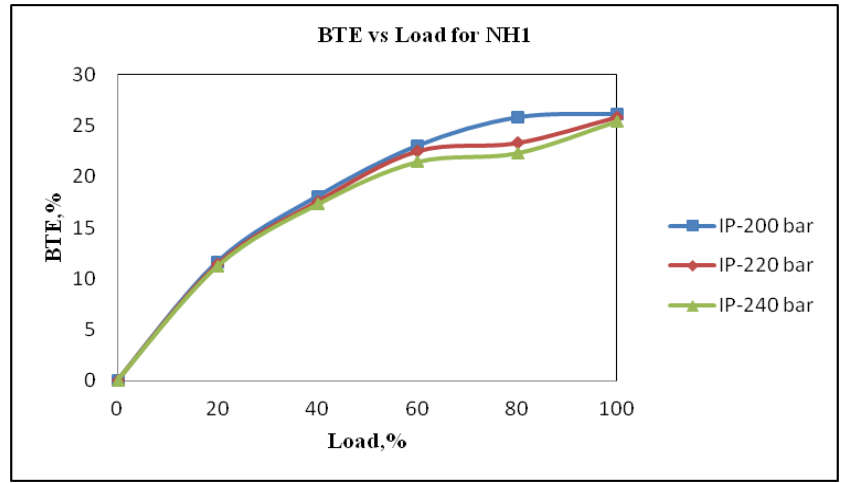

Fig.3.Variation of BTE vs Load for NH1

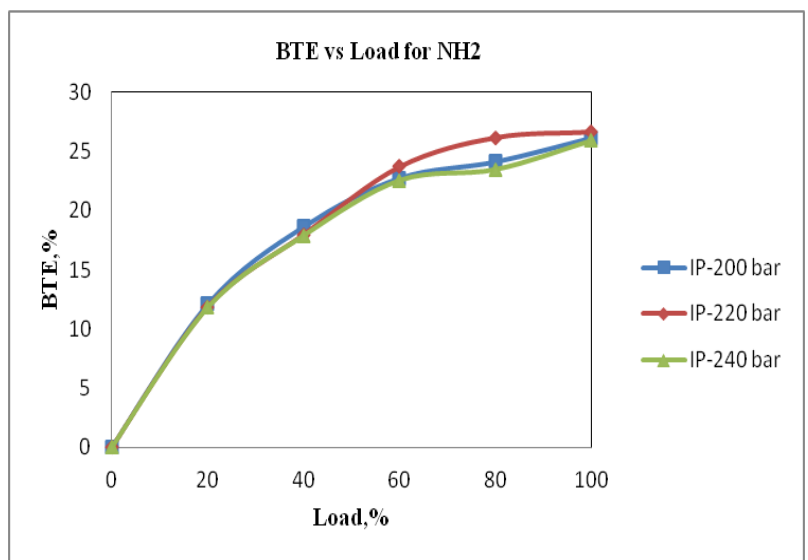

Fig.4.Variation of BTE vs Load for NH2

\section{B. Effect on Brake Specific Fuel consumption (BSFC)}

Effect of nozzle hole geometry for NH1and $\mathrm{NH} 2$ on brake specific fuel consumption is as shown in Fig.5-6 respectively. The experiments were aimed to arrive at an optimum nozzle size and fuel injection pressure that would give better fuel economy. It can be noticed from the Figs.5-6 that the values of BSFC are lower for an IP of 220 bar compared to IP of 200 bar and 240 bar. Further increase in the IP beyond 220 bar has resulted in higher values. This could be due to the fact that with increase in injection pressure, not only the fuel droplet size decreases but also increases the momentum of the droplets. Therefore, too high increase in pressures would have developed even small droplets but with increase in momentum the droplets could have got impinged on the cylinder inner wall and to develop same power, the fuel consumption should have increased. Thus, at the prevailing conditions, an IP of 220 bar yielded lower BSFC. It can be observed that BSFC with NH2 and IP 220 bar is the lowest, therefore from these set of experiments it is confirmed that the NH2 and IP of 220 bar yielding lower values. Also, it was observed that for the small size hole nozzle at any given injection pressure yielded better performance. This is indicating the fact that smaller nozzle requires higher injection pressure to ensure complete combustion and to bring down fuel consumption.

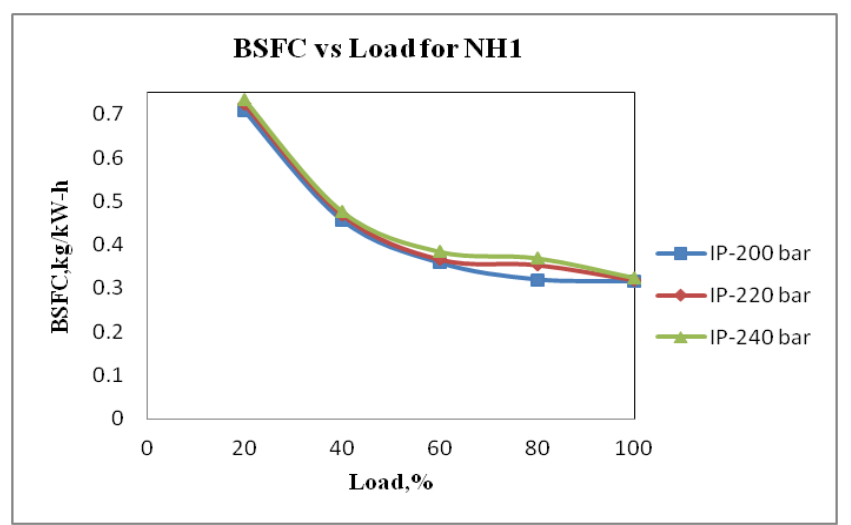

Fig.5.Variation of BSFC vs Load for NH1 


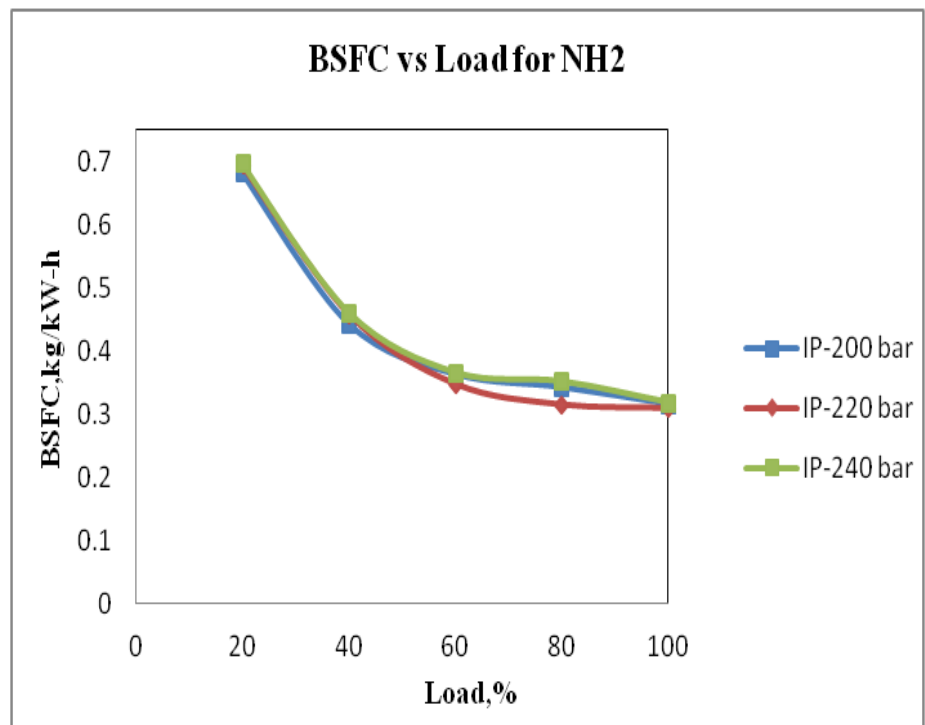

Fig.6.Variation of BSFC Vs Load for NH2

\section{Effect on Nitrogen Oxides $\left(\mathrm{NO}_{\mathrm{x}}\right)$ emission}

Effect of nozzle hole geometry and IP on $\mathrm{NO}_{\mathrm{x}}$ emission as shown in Figs.7-8 respectively. $\mathrm{NO}_{\mathrm{x}}$ emission is result of oxidation of nitrogen at peak combustion temperature. At any nozzle hole operation with increase in IP, $\mathrm{NO}_{\mathrm{x}}$ emission was found to be increasing due to faster combustion and higher temperatures reached in the cycle as shown in the Fig.7-8. This may be attributed to better atomization and improved mixing rate of fuel responsible to reduce delay period, and combustion duration, corollary it results in improved heat release rate, peak combustion and temperature. However, at IP 240 bar at $60 \%, 80 \%$ or full load for NH1, the $\mathrm{NO}_{\mathrm{x}}$ emissions reduced for due to lower combustion phase and incomplete combustion caused by poor atomization, sprays characteristics and increased ignition delay at this pressure. Higher $\mathrm{NO}_{\mathrm{x}}$ emissions were observed with increased number of holes. The NH-2 injector provides better air and fuel mixing and hence higher premixed combustion occurs leading to higher NOx emissions.

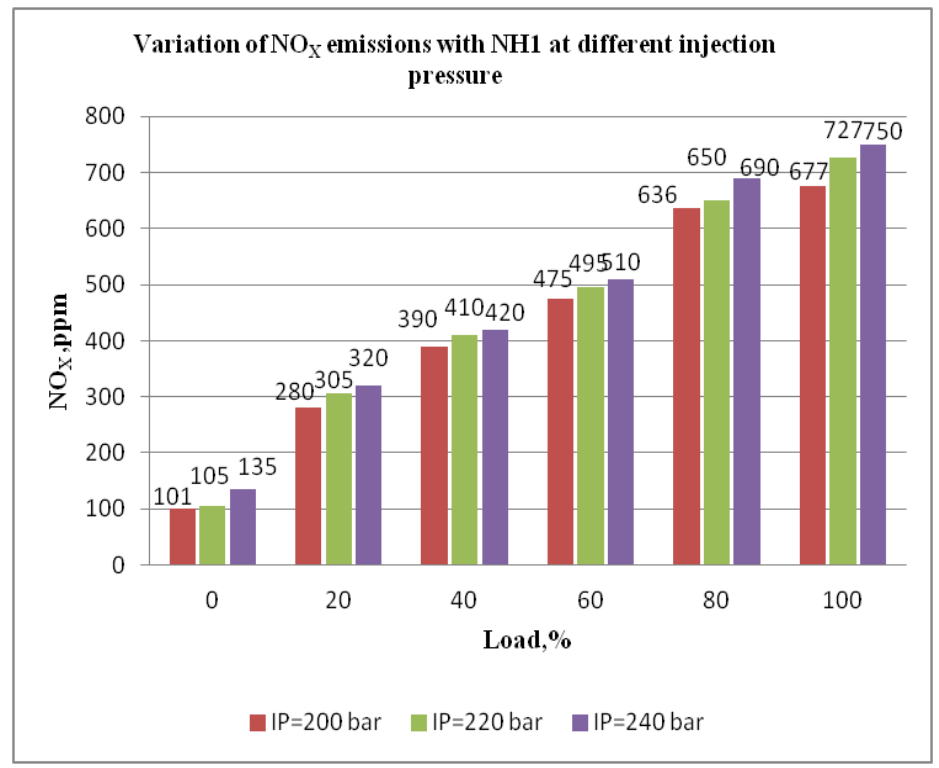

Fig.7.Variation of $\mathrm{NO}_{\mathrm{x}} \mathrm{Vs}$ Load for $\mathrm{NH1}$ 


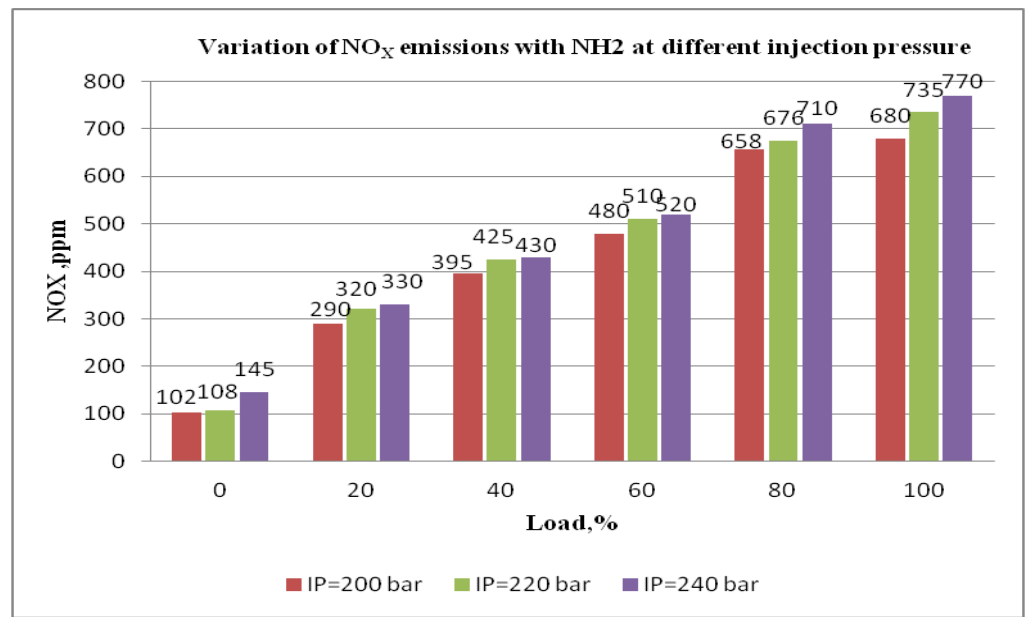

Fig.8.Variation of $\mathrm{NO}_{\mathrm{x}} \mathrm{Vs}$ Load for $\mathrm{NH2}$

\section{Effect on Carbon monoxide oxides (CO) emission}

Effect of nozzle hole geometry and IP on CO emission as shown in Figs.9-10 respectively. As we know that $\mathrm{CO}$ emission is nothing but behaviour of incomplete combustion due to rich air-fuel mixture. Thus, due to increase in load from $80 \%$ to full load, $\mathrm{CO}$ emission for all tests was found to be increased. In addition, $\mathrm{CO}$ emission was found to be decreased with increase in nozzle hole and IP. This adds advantage of increasing IOP and nozzle hole up to certain limit. However at IP 220 bar and NH-2 injector, CO emissions are less which is due to improved atomisation and proper combustion.

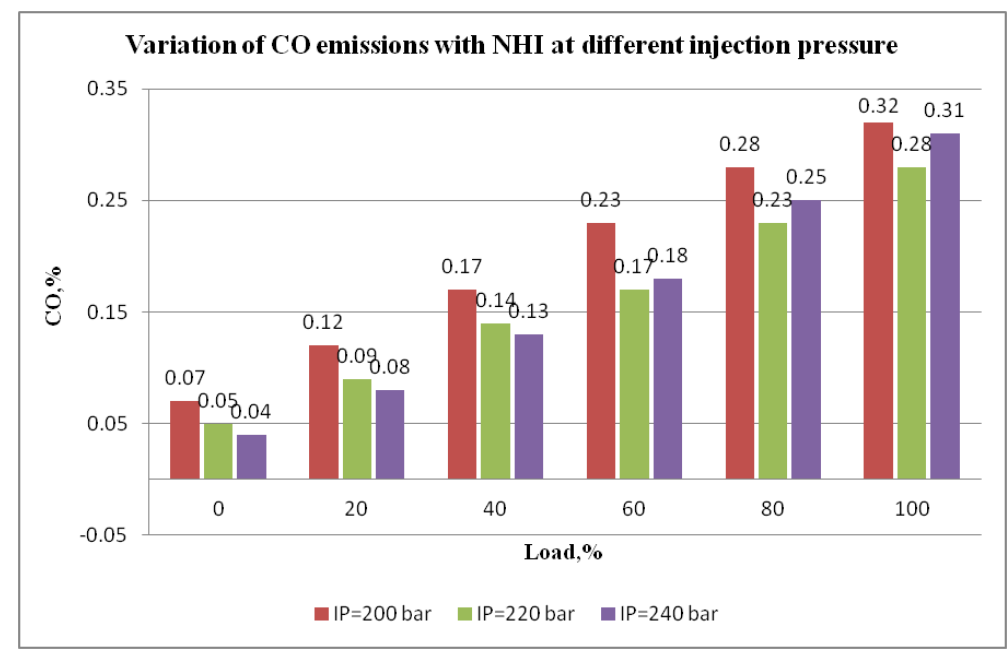

Fig.9.Variation of CO Vs Load for NH1

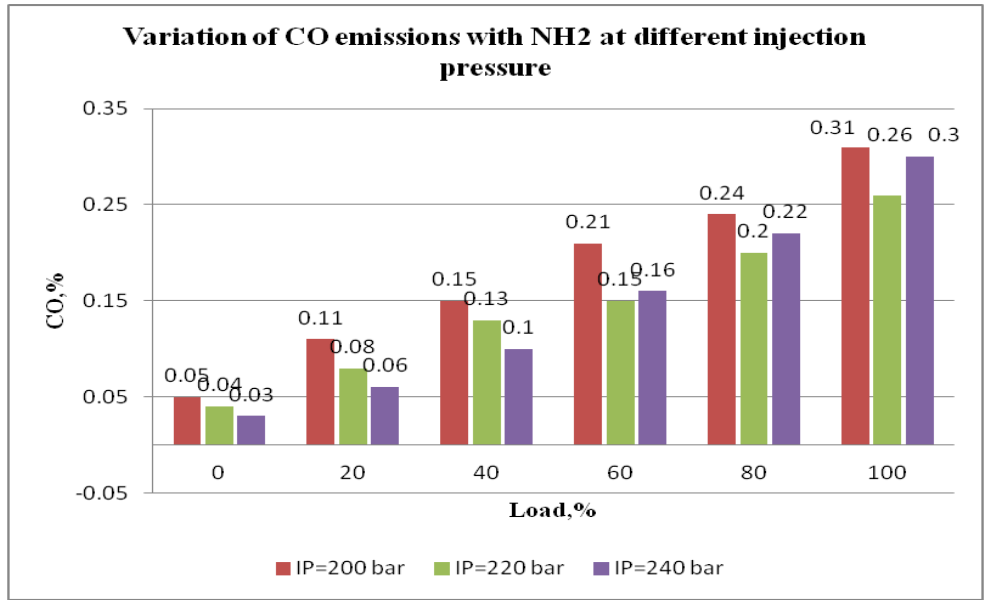

Fig.10.Variation of CO Vs Load for $\mathrm{NH2}$ 


\section{E. Effect on Hydrocarbons (HC) emission}

Effect of nozzle hole geometry and IP on HC emission as shown in Figs.11-12 respectively. We know that, $\mathrm{HC}$ emission is caused due to low velocity of fuel which is not sufficient to penetrate air spray and induced improper air-fuel mixing or lower equivalence ratio (Ø). Also, more emission is found due to lack of fuel atomization or vaporization. As seen in Figs.11-12, for all nozzle hole operation HC emission was decreased with increase in IP. However at IP 220 bar and NH-2 injector, HC emissions are less which is due to improved atomisation and proper combustion. Enhanced atomisation will also lead to a lower ignition delay.

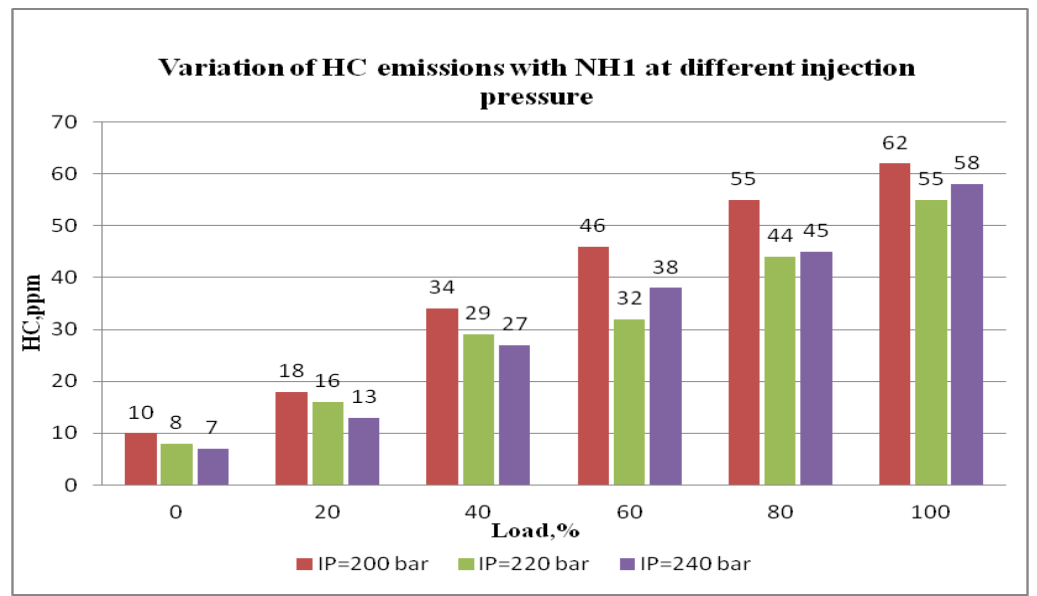

Fig.11.Variation of HC Vs Load for NH1

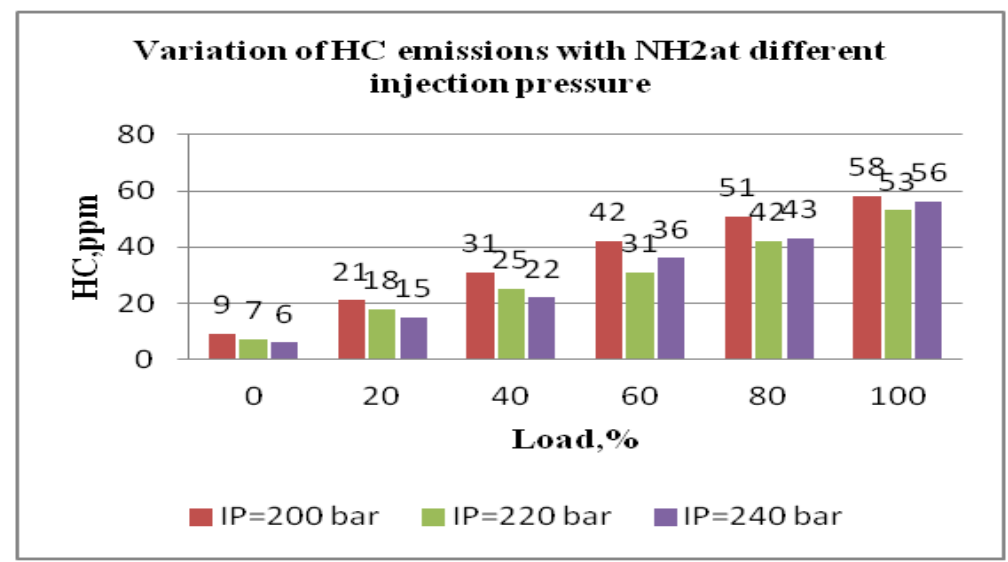

Fig.12.Variation of HC Vs Load for NH2

\section{E. Effect on Smoke opacity}

The Smoke opacity values obtained is shown in Fig.13-14. The trends of smoke opacity values are similar to HC emissions. In addition, smoke opacity was found to be decreased with increase in nozzle hole and IP.

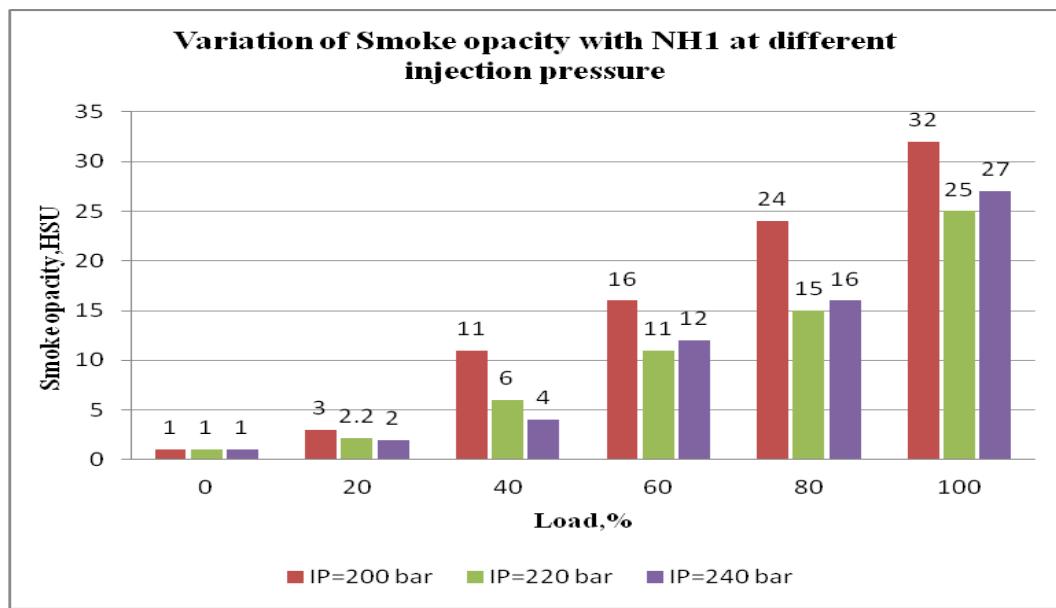

Fig.13.Variation of Smoke opacity Vs Load for NH1 


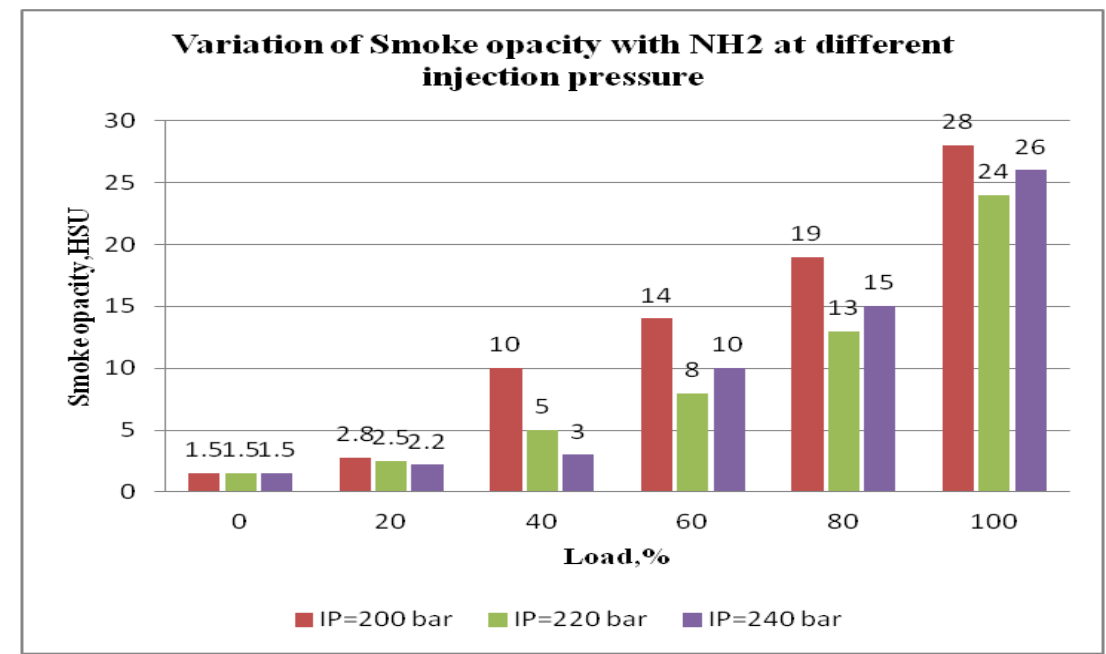

Fig.14.Variation of Smoke opacity Vs Load for NH2

\section{Conclusions}

The Brake thermal efficiency for 5 hole nozzle at full load was found increasing in the order of 240200-220 bar injection pressure and brake specific fuel consumption found decreasing in the order of 240-200220 bar injection pressure. Though at 220 bar higher brake thermal efficiency and lower brake specific fuel consumption were obtained the percentage of improvement was maximum of $3 \%$. So, increasing injection pressure and number of holes gave considerable effect on engine performance.

At full load, $\mathrm{CO}$ and $\mathrm{HC}$ emissions were found lowest at $220 \mathrm{bar}, \mathrm{NO}_{\mathrm{x}}$ was found lowest at $200 \mathrm{bar}$ and smoke density was found lowest at 220 bar.CO was $16 \%$ and $13 \%$ and $\mathrm{HC}$ was $8 \%$ and $5 \%$ lower compared to 200 bar and 240 bar respectively. $\mathrm{NO}_{\mathrm{X}}$ emission was $7 \%$ and $11 \%$ lower compared to 220 bar and 240 bar respectively. Smoke density was $14 \%$ and $7 \%$ lower as compared to 200 bar and 240 bar.

The economy of fuel is important for engine. At present scenario environmental protection is more important than fuel economy. So, decreasing emission is the primary concern which required moderate injection pressure for a light duty diesel engine.

\section{References}

[1] Seang-wock Lee, Daisuke Tanaka, Jin Kusaka, Yasuhira Daisho. 2002. Effects of diesel fuel characteristics on spray and combustion in a diesel engine. JSAE Review. 23: 407-414.

[2] S. P. Wategave , M. S. Sawant, M. S. Tandale, G. Suresh , V. S. Yaliwal , N. R. Banapurmath \& P.G. Tewari. 2013. Effect of injection timing, injector opening pressure and nozzle geometry on the performance of a compression ignition engine operated on non-edible oil methyl esters from different sources, International Journal of Sustainable Engineering, DOI:10.1080/19397038.2013.777134.

[3] Ganesan V. Engine emission and their control, "Internal combustion engines" (McGraw Hill,ND, 3rd ed., 2008, page 471-500).

[4] Rosli, Abu Bakar, Semin, and Abdul Rahim Ismail. 2008. Fuel Injection Pressure Effect on Performance of Direct Injection Diesel Engines Based on Experiment. American Journal of Applied Sciences 5 (3): 197-202.

[5] Celikten, Ismet. 2003. An experimental investigation of the effect of the injection pressure on engine performance and exhaust emission in indirect injection diesel engines, Applied Thermal Engineering 23, pp: 2051-2060.

[6] M.L.S Deva Kumar, S.Drakshayani, K.Vijaya Kumar Reddy.2012. Effect of Fuel Injection Pressure on Performance of Single Cylinder Diesel Engine at Different Intake Manifold Inclinations. International Journal of Engineering and Innovative Technology. ISSN: 2277-3754.

[7] Bakar, R.A., Semin., Ismail, A.R. and Ali, Ismail. 2008. Computational Simulation of Fuel Nozzle Multi Holes Geometries Effect on Direct Injection Diesel Engine Performance Using GT-POWER. American Journal of Applied Sciences 5 (2): 110-116. 